\title{
The Words Made Fresh: Transforming the Language and Context of Faculty Development
}

\section{Marie Wunsch}

University of Hawaii, Manoa

$\mathrm{O}_{\text {ne of the main challenges faced by those who create, implement, or }}$ revitalize faculty development programs is making the language of development palatable, even positive, to faculty. Allan Tucker (1988) reminds us that the term, "'faculty development,' for all its good intentions, often offends faculty who see the term as demeaning to their hard-earned Ph.D.'s," and that a "faculty development director underscores the remediation stigma in many minds."

Since Tucker is only articulating an attitude we all face at one time or another, what is the sensitive and semantically adept faculty developer to do? There are the usual euphemisms to try, such as "professional growth," "revitalization," "instructional enhancement," "holistic renewal," and "career redirection," most of which elicit cynicism and charges of semantic manipulation. At the University of Hawaii, we tested them all and found little agreement on any specific language.

Faculty members, by virtue of our education and political instincts, are an individualistic lot especially given to debate and criticism. Questions of semantics appear to bring out particularly strong academic passions. Therefore, the effective faculty developer must recognize the passion, identify with the faculty proclivity to examine and debate, attempt to build an ethos receptive to development, go on to transform the institution, and thus bring fresh meaning to the language of "development" within the institutional context. 
A weed by another name can be an exotic flower, and gardeners know that the best results depend on when and where the manure is put out. If a faculty development program is to flower, the needs and aspirations of the faculty must be met. The terminology becomes merely the reference point. If transformation of the institution is the goal, it will drive the transformation of the language. Institutional transformation, while a visionary concept, can come to fruition with systematic planning and semantic support.

\section{Combining Faculty Development and Faculty Support}

The faculty development program at the University of Hawaii came about through a systematic and comprehensive two-year planning process that sought extensive faculty and administrative participation. The process began with the traditional needs assessment survey, which allowed respondents to identify those aspects of campus policy, infrastructure, and instructional environment that hindered their work as teachers and scholars. After identifying problems, the faculty could place a priority on which of these should be addressed during the first three years of a program.

To ensure sensitivity to responses from all of the diverse groups that compose a comprehensive research university faculty, twelve open forums were held with various constituencies, including senior, junior, women, minority, foreign and visiting faculty, lecturers, and graduate research and teaching assistants. Each group had its particular interests or specialized needs for development and support. More than $\mathbf{3 8 5}$ faculty members played an active role in this assessment and development phase; we interpreted this strong participation as a sign of extraordinary interest and success early in the program.

The issue of "development" language was a recurrent theme throughout the forums. Predictable responses centered on the implication that "development" was associated with "remediation," "failure to meet expectations," "incompetent." A second pattern emerged, however, which interpreted "development" as a support mechanism. Faculty members constantly assess and fine-tune their teaching and scholarly skills. What often requires development, therefore, is not the faculty member, but the faculty support system, which should encourage, fund, and reward productivity. 
As a result of these insights, the University of Hawaii administration proposed establishing an Office of Faculty Development and Academic Support. Under the leadership of the Vice President for Academic Affairs, the portfolio of faculty development was broadened to include traditional academic support activities, such as the media resources center, computer-assisted instruction, classroom maintenance and improvement, a research unit on multicultural higher education, curriculum development grants, faculty workshops, convocations, award ceremonies, and administrative development activities for department chairs. Since the program is a probationary one, a formal evaluation will be required by the University after five years. During the initial two-year developmental period, we have evaluated the program based on the number of faculty members participating in specific activities, such as the workshops, seminars, convocations, inquiry groups, and diagnostic evaluations, and on participants' ratings of these activities. Both attendance and ratings have been very high.

A key strategy for institutionalizing and securing faculty development and support is to ensure that the language of development is used consistently in regular institutional policy and procedural documents, such as the academic development plan, the legislative budget requests, the repair and maintenance plans, and the guidelines for faculty evaluation, promotion, and tenure. It then becomes clear that development goes beyond what we do to faculty, to what we do for and with them as an institution.

This approach is more inclusive than the early models for faculty development programs cited by Bergquist and Phillips (1975). These early models focus on instructional development and individual skill enhancement; our approach is more closely related to the broader concepts advocated by Clark, Corcoran, and Lewis (1986), who interrelate faculty and institutional vitality and make a case for an institutional perspective on faculty development that is based on a human resource development model. Our good fortune came in starting a program late in relation to other comparable universities and in having many excellent program models to consider.

\section{Linking Faculty Development and Faculty Evaluation}

Experienced faculty developers almost universally advise dissociating evaluation for merit, promotion, and tenure from development. Within most institutional contexts, this is excellent advice. We have found, how- 
ever, that the two functions can be linked as mutually beneficial activities in the case of periodic review of tenured faculty. While only a few research universities have as yet instituted formal post-tenure review programs, a growing literature supports the view that evaluation can act as a catalyst for faculty development. The key is to integrate both in a way that nurtures faculty growth and institutional excellence (Andrews, 1985; Arreola, 1983; Licata, 1986).

Indeed, evaluation practices that exist in isolation from development may cause deeper alienation, especially among tenured faculty. And if evaluations include feedback on performance, then a professional development plan that draws on the resources of a campus development program linking assessment with development may be a very viable avenue to improvement.

The linkage between evaluation and development on our campus evolved as a result of an event that occurred at about the same time we were working to design and implement the faculty development program. After a three-year process that took the University Board of Regents and the faculty union, the University of Hawaii Professional Assembly (UHPA), to the Hawaii Supreme Court, a ruling confirmed that management had the right to evaluate faculty and that the evaluation process was not a negotiable item. The ruling reactivated a long-standing, but not fully implemented, Board of Regents policy requiring that all faculty be formally evaluated every five years. Each academic department was required to agree on expectations for faculty within the department mission and goals. Under these guidelines, the department chair served as the primary evaluator. The only group not routinely subject to review under the new procedures was senior tenured faculty. The evaluation thus took on the aura of a "post-tenure review."

Given this situation, the fledgling faculty development program risked being viewed by some faculty members and administrators as a ruse to soften the effects of the review or to focus on "deadwood" not meeting expectations. Some department chairs thought that they would be able to remand faculty to the program for required "fix-ups."

Transformational language, however, can influence even such a potentially negative situation. Rather than take an adversarial stance, UHPA and the administration agreed to develop a mutually acceptable procedure for the review. The university's commitment to the faculty is thus reflected in the language of the procedures, as is the union's advocacy of academic freedom. The Preface (1987) states: 
Evaluation can be a positive force when used to encourage members of the University community to continue their professional growth and thereby improve the delivery of their professional services. To this end, the institutional resources must be committed to incentive programs which support faculty development in the areas of teaching, research, and service.

Evaluation of faculty must not undermine the concepts of academic freedom and tenure ... there is a presumption of competence on the part of each tenured faculty member ... the Manoa Faculty Development Committee was established by the procedures to assist individual faculty members who do not meet expectations in arriving at a successful development plan for meeting the expectations of their department.

The document goes on to say "that the interaction of the Committee with faculty members is intended to be positive and supportive."

During the 1987-88 cycle of review, 245 tenured faculty were subject to evaluation. Of this group, 46 who did not meet expectations formulated approved professional development plans with their department chairs or deans or with the counsel of the Faculty Development Committee. During 1988-89, all are actively carrying out these plans, a measure of success we find encouraging. UHPA conducted a survey of the faculty at the end of the first cycle and concluded that the faculty judged the process to be just, equitable, and humane. We are keenly aware, however, that our experiment is at an early stage and that the operational efficiency of the evaluation side must be matched by continued moral and financial support on the development side.

Linking faculty evaluation directly with faculty development has therefore become a way of enhancing a positive institutional climate whereby faculty are encouraged and supported even during periods of their careers when they may not be fully productive. A supportive academic culture requires that faculty be treated with respect and dignity and recognizes that development is a highly complex process that demands attention to individual needs within the department mission and is attuned to the stages of faculty careers.

\section{Cultivating Culture, Climate, and Community}

In Academic Culture and Faculty Development (1979), Mervin Freedman proposes that faculty development be seen "as a process of unfolding, of making latent processes active, of increasing amplitude, of evolving to 
a higher state," and argues that good teaching and scholarship "depend on the inner state of mind, on faculty values and attitudes." Inherent in the success of a faculty development program are the shared vision, the values, and the attitudes of the participants and advocates. For example, while collegiality clearly is essential in the planning and implementing of a program, the very support of the administration may arouse suspicion and cynicism among faculty on a campus with a history of conflict over evaluation and development. In this situation, the language of development may sharpen the double-edged sword. Faculty who most need improvement may distrust even those publicly pledged to support them and see the development program as a means of eroding their individual choice. A development program thus needs the widest base in order not to be identified only with the needy.

Among the strategies supporting faculty development within an institutional context must be an emphasis on enhancing, recognizing, rewarding, and highlighting the vitality of successful and productive faculty members. If a faculty development program is presented as a group of interrelated services providing a menu of possibilities that enhance the working environment, we can create a climate and sense of community. Traditional activities such as convocations, orientations, open inquiry groups, colloquia, ceremonies and rituals honoring accomplishment, and workshops on teaching, student learning, grantsmanship, scholarly writing, and classroom research announce support for these expectations of the Academy. While some of these activities are ongoing in specific departments and colleges of the University of Hawaii, the creation of the Center for Teaching Excellence and an Office of Faculty Development and Academic Support has brought together faculty across disciplines to focus on common concerns. For example, a workshop and classroom presentation on the professional voice by a former Shakespearean actor and professor emeritus garnered an audience of $\mathbf{9 6}$ faculty members.

All who share in its ranks are responsible for nurturing the academic community. Developing a climate of vitality, renewal, and transformation can only enhance and legitimize the development of faculty.

On an urban commuter campus like ours, establishing a sense of community among faculty is as difficult as managing one for students. To solidify faculty attachment to the University of Hawaii through identification with the larger Academy, we re-established a series of ritual events with appropriate pomp and circumstance. Faculty members were invited to and did attend the Student Opening Year Convocation in academic regalia (no small factor in the 90-degree Honolulu afternoon). Colleges 
carried medieval-style banners designed with their own motifs to create what Harvey Cox calls "a festival of the spirit." Faculty also came together in a separate Faculty Convocation, and in welcoming remarks by the President, members of the Board of Regents, the Faculty Senate, and a keynote faculty speaker were reminded that congregating together in academia is a long and honored tradition for scholars and students.

The complementary event that ends the academic year is a ceremony honoring faculty members selected for excellence in teaching and research awards. The recipients report that it is especially gratifying to be recognized by their peers in a public event. The awards, consisting of medals and a cash prize, are given by the Board of Regents upon recommendation by the President. Nominations may be made by students, faculty, staff, and alumni and are screened by college-level committees and the campus Honors and Awards committee. The awards remain prestigious because of the rigorous selection and peer review process.

As Bellah et al. reminded us in Habits of the Heart (1985), "a real community is a community of memory ... that must tell its story often... and offer examples of its vision through the men and women who embody and exemplify the collective dreams ... tradition is central to the community of memory." Creating and nurturing a sense of community is the broadest mission of faculty development and is a goal that can bring out the best spirit as well as the most productive work from the community's members.

In the gardens that we cultivate, "faculty development" and the language that surrounds, supports, and symbolizes it can take on a proud and visible legitimacy. "Development" can be a word that suggests potential, regeneration, recognition, and resurgence of the best within us. Faculty will come to live with the local definition of development programs if these programs are institutionally integrated and supported, and complex enough to recognize faculty diversity and values. When faculty development is combined with faculty support and faculty recognition, the combination is powerful in both its symbolism and semantics, and faculty can become its greatest advocates.

\section{References}

Andrews, H.A. (1985). Evaluating for excellence. Stillwater, OK: New Forums Press, Inc.

Arreola, R.A. (1983). Establishing a successful faculty evaluation and development program. In A. Swift (Ed.), Evaluating faculty and staff. New directions in community colleges, No. 41. San Francisco, CA: Jossey-Bass. 
Bellah, R.N., Madsen, R., Sullivan, M., Swindler, A., and Tipton, S. (1985). Habits of the heart: Individualism and commitment in American life. New York: Harper and Row.

Bergquist, W.H., and Phillips, S.R. (1975). A handbook for faculty development. Washington, DC: The Council for the Advancement of Small Colleges.

Clark, S., Corcoran, M., and Lewis, D.R. (1986). The case for an institutional perspective on faculty development. Joumal of Higher Education, 57(2), 176-195.

Freedman, M. (1979).Academic culture and faculty development. Berkeley, CA: Montaigne Press.

Licata, C.M. (1986). Post-tenure faculty evaluation: Threat or opportunity. Washington, DC: ASHE-ERIC Higher Education Report No. 1.

Procedures for the Evaluation of Faculty at the University of Hawaii, Manoa. (February 1987).

Report to the Board of Regents of the University of Hawaii on the Evaluation of Tenured Faculty. (June 1988).

Tucker, A. (1988). Faculty development and academic semantics. Academic Leader, 4(4), 2-3. 